\title{
Seepage-Stress Coupled Analysis on Shield Tunnel Face Stability in Layered Soil
}

\author{
Yongli Fan ${ }^{1, \text { a }}$, Zemin Ren ${ }^{2, b}$, Kun Liu ${ }^{2, c}$, Jinli Qiao ${ }^{3}$, Xia Chen ${ }^{1}$ \\ ${ }^{1}$ Tianjin long xing building materials co., Ltd, Tianjin,301606, China \\ ${ }^{2}$ Campus Planning Department, Hebei University of Technology, Tianjin, 300401, China \\ ${ }^{3}$ School of Civil Engineering, Hebei University of Technology, Tianjin, 300132, China

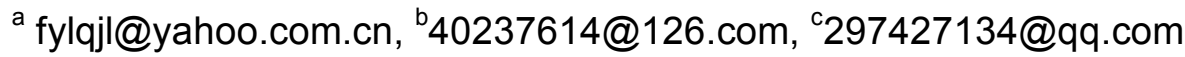

\begin{abstract}
Keywords: face stability; seepage field; stress field; coupling; limit support pressure
Abstract. Shield tunnel face stability in layered soil is becoming the important problem on the underwater. Seepage-stress coupled on the tunnel face is analyzed using fast Lagrangian method and discussed the effect of seepage force on face stability, and the relation is analyzed between the face pressure and the deformation of tunnel face. According to the stability theory, the limit support pressure that displacement of the center at tunnel face increases large suddenly when face pressure is changed very small is compared with the result of reference [7] by wedge body limit equilibrium, the error is only $5.7 \%$ and reasonable. The support pressure provide convincing computing results for the minimum pressure of tunnel face in design and construction and the support method to prevent the collapse of tunnel face. Comparing the plasticity, stress, displacement of the tunnel face under seepage force, it is showed that seepage-stress coupled has a bad effect on the stability of tunnel face, the support pressure is equal to the total of the effective face pressure and seepage force and the seepage force is the most of the total support pressure. The influence of pore water pressure on the stress and displacement and stability of tunnel face is large and not ignored. By comparison of coupling of fluid-solid effect, it is found the seepage force is the most of the total face pressure and the exist of underwater has the disadvantage influence on stability of tunnel face and not ignored.
\end{abstract}

\section{Introduction}

The stability of shield tunnel face coupled by seepage-stress with large diameter in layered soil is a complex and important subject in this field. The main reason of ground deformation in the shield construction is whether the control of propulsive force of the tunnel face keeps balance with its soil pressure. The support pressure of the excavation face should avoid following cases. On the one hand, the pressure is not enough to support, and the tunnel face collapse. On the other hand, the pressure is excessive, the surface uplift. The research of excavation face support pressure pays more attention to the limit excavation face support pressure recently.

In the fluid-structure coupled model, Ji Xiaoming[1] etc. calculate the question of hydraulic coupled. They think that the displacement around tunnel and the maximum shear stress are bigger by considering percolation. In the research of tunnel face, Pierre Chambon and Jean-Francois Corte[2] etc. measure the limit support pressure of the even soil without the function of groundwater by centrifuge test. G. Anagnostou and K. Kovari[3] etc. research shield tunnel face stability in the even soil when the soil pressure maintains balance. Lee and Seok-Woo[4] etc. conduct limit equilibrium analytical analysis about uniform soil stability by considering percolation, the result coincide with the result of centrifuge test. W. Broere [5] etc. research the limit support pressure of layered soil by wedge body limit equilibrium without the function of groundwater. Qin Jianshe[6] etc. analyze shield tunnel excavation face limit support pressure and stability in the superficial layer of sandy soil. In this paper the complex soil such as special parameters of the soil and the ground water affect the limit support pressure and stability of tunnel excavation face. M.A. Meguid and R.K. Rowe[7] analyze the stability of D-shaped tunnel excavation face without considering seepage effect. 
In many studies, the coupling analysis of shield tunnel excavation face in layered soil is few. In this paper, the stability of shield tunnel excavation face is analyzed by the finite difference numerical method with the foundation of fluid solid coupling theory. It is discussed that the plastic stage, stress and displacement of shield tunnel excavation face are affected by the pore water pressure under the influence of fluid solid coupling. According to the basic principle of stability theory, support pressure is defined limit support pressure when the petty change of excavation face support pressure leads to a abrupt change of the displacement in the central point of excavation face, and calculate the figure.

\section{The principle of fluid solid coupling analysis}

Deformation from stress analysis should be applied to differential equation to solve pore water pressure that reflect the fluid solid coupling relationship. After the calculating value of each point pore pressure value in the seepage field, effective stress of each unit in seepage field is calculated according to the principle of effective stress. In the process of calculation, rock is regarded as equivalent continuum, and fluid accord to Darcy's law in the medium.

The basic equations of saturated soil seepage stability:

$\frac{\partial}{\partial x}\left(k_{x} \frac{\partial h}{\partial x}\right)+\frac{\partial}{\partial y}\left(k_{y} \frac{\partial h}{\partial y}\right)+\frac{\partial}{\partial z}\left(k_{z} \frac{\partial h}{\partial z}\right)=0$

In this formula, $\mathrm{k} \_\mathrm{x}, \mathrm{k} \_\mathrm{y}, \mathrm{k} \_\mathrm{z}$ is permeability coefficient of the $\mathrm{x}, \mathrm{y}, \mathrm{z}$ direction, $\mathrm{h}(\mathrm{x}, \mathrm{y}, \mathrm{z})$ is the water head of one point.

\section{The coupling model of seepage filed and stress field of tunnel face}

Project overview. Shanghai Yangtze River tunnel project is the highway tunnel connecting Shanghai and Chongming and an important part of Chinese coastal highway, which owns the biggest diameter in the world iand through the composite soil and under the high water pressure. Yangtze River tunnel project cross the Yangtze River South by tunnel and connect Pudong and Changxing Island, which length is $25 \mathrm{~km}$. In this paper, $\mathrm{K} 2+373$ is selected as the representative research object according the measured data, which is under the Yangtze River. The material parameters is shown in Table 1.

Table1 Parameter of materials

\begin{tabular}{llllllll}
\hline $\begin{array}{l}\text { layer } \\
\text { number }\end{array}$ & $\begin{array}{l}\text { layer } \\
\text { thickness } \\
(\mathrm{m})\end{array}$ & $\begin{array}{l}r \\
\left(\begin{array}{l}\mathrm{KN}^{3} \\
\mathrm{~m}^{3}\end{array}\right)\end{array}$ & $\begin{array}{l}\mathrm{C} \\
(\mathrm{KPa})\end{array}$ & $\begin{array}{l}\varphi \\
(\circ)\end{array}$ & $\begin{array}{l}E_{s} \\
(\mathrm{MPa})\end{array}$ & $K_{0}$ & $\begin{array}{l}K_{h} \\
(\mathrm{~cm} / \mathrm{s})\end{array}$ \\
Silt soil & 2.0 & 17.3 & 12 & 14.5 & 2.89 & 0.75 & \\
Sandy silt & 2.0 & 18.6 & 6 & 31.5 & 8.47 & 0.34 & $1.15 \mathrm{e}-3$ \\
Silt clay & 9.7 & 16.8 & 10 & 11.0 & 2.22 & 0.66 & $5.42 \mathrm{e}-7$ \\
Clayey silt & 2.8 & 18.2 & 11 & 26.5 & 5.94 & 0.55 & $1.02 \mathrm{e}-4$ \\
Silty clay & 25 & 18.0 & 17 & 18.5 & 4.24 & 0.48 & $3.21 \mathrm{e}-6$ \\
Sandy silt & 5 & 18.6 & 8 & 30.5 & 9.90 & 0.38 & $4.59 \mathrm{e}-4$ \\
Clayey silt & 9.5 & 19.1 & 4 & 33.5 & 15.7 & 0.33 & $3.20 \mathrm{e}-3$ \\
Gravel sand & 4.45 & 19.1 & 3 & 34.5 & 16.9 & 0.32 & $3.65 \mathrm{e}-3$ \\
\hline
\end{tabular}

The feasibility of way to calculate tunnel face limit support pressure. Tunnel face support pressure is represented by support stress of the point of tunnel face center with considering that the actual support pressure in tunnel face is trapezoidal load, which is the pressure of the point in the center of tunnel face. To express the value of tunnel face support pressure, support stress ratio concept is led into:

$$
\lambda=\frac{\sigma_{s}}{\sigma_{0}}
$$


In this formula, $\sigma_{\mathrm{s}}$ is the support stress of the point in the tunnel face, $\sigma_{0}$ is the original horizontal static soil pressure in the center of tunnel.

To ensure the feasibility of this method, compare the result with the model in the reference [7]. The calculation model is depicted in Figure 1. According to the wedge limit equilibrium in reference [7], limit support pressure is $199 \mathrm{KPa}$. Compared the result with it, the result is shown in Figure 2 . The limit support ratio calculated in this paper is 0.33 . The limit support pressure is $181.94 \mathrm{KPa}$. The support ratio is 0.41 and the support pressure is $233.11 \mathrm{KPa}$ when the level displacement of the point in the tunnel center is $1 \mathrm{~m}$. The method in this paper is similar to the reference [7], and the error is 5.7\%. The error of support pressure is $17.1 \%$ when the level displacement of tunnel face is $1 \mathrm{~m}$. So the method is feasible.
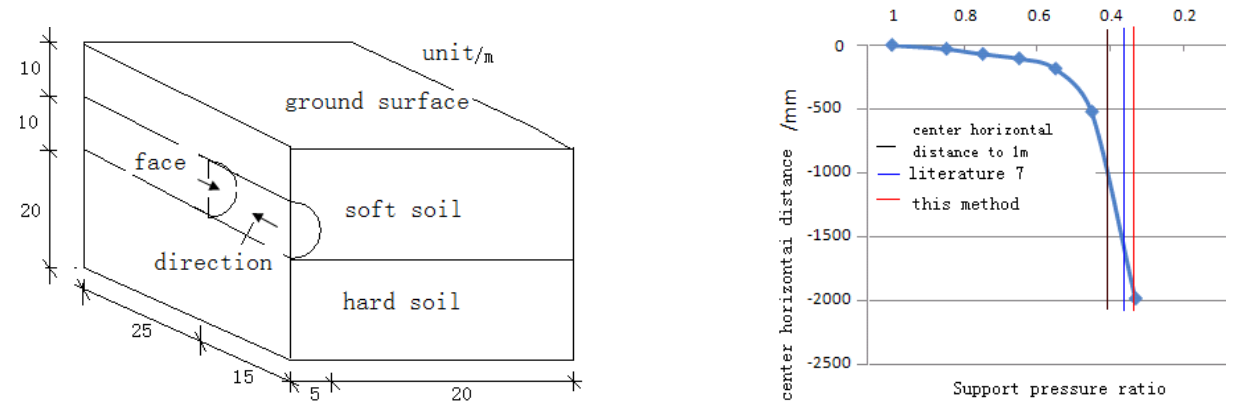

Fig.1 The model of calculation Fig.2 Comparison of support stress in different methods

Establish the model of the calculation in engineering example. Considering complex layer soil and the uncertain location of tunnel, simplify the analysis of layer soil. The analysis model of seepage is shown in Figure 3(m). The level of underground water is $5 \mathrm{~m}$ far from the surface. As for seepage influence, fluid modeling and mechanical modeling is established in parallel. First, conduct seepage analysis, store the pore water pressure of each point and total water head. Then calculate head gradient value of each point through the total water head, and store the seepage pressure as nodal force. Finally seepage force from seepage analysis is applied to the stress analysis as boundary force conditions. When the limit support pressure is confirmed, the tunnel face support pressure as cross-range static soil pressure in the center of tunnel face, then slowly decrease the pressure, and make the curves of the support pressure ratio and the displacement in the center of tunnel face. As the support ratio decreases, the horizontal displacement of the point in the center of tunnel face is gradually reduced, while the displacement increases rapidly, the support pressure in this time is the minimum support pressure.

The calculation model is shown in Figure 4 . The model is applied 8 nodes entity unit grid. There are 26035 nodes and 24000 units.

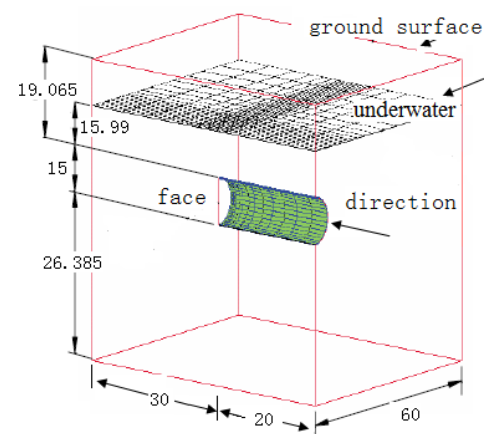

Fig. 3 The model of seepage analysis

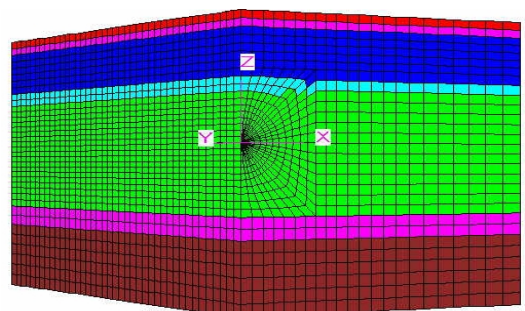

Fig.4 Grid and stratum distribution model

\section{Coupling calculation result analysis of the tunnel face seepage field and stress}

The fluid can flow through the soil pore under the head difference. When the tunnel excavate in the soil under water level, groundwater flow into the tunnel face, and the seepage may influence the tunnel excavate support and the stability of tunnel face. 
Tunnel face limit support pressure.

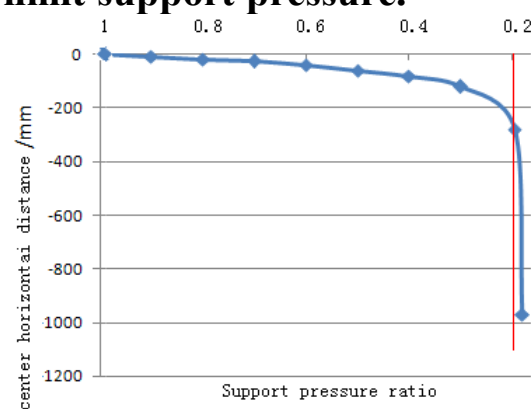

(a) no seepage

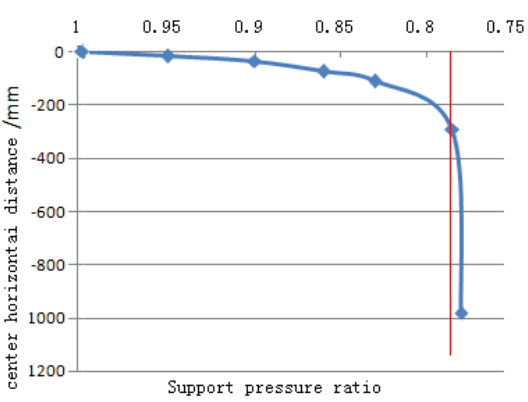

(b) seepage

Fig.5 Relationship between support stress ratio and displacement under

It can be seen from Figure 5(a,b) that the support pressure ratio is 0.19 and 0.785 under no seepage and seepage. The seepage force constituting the main part is the $82.86 \%$ of the total support pressure, cannot be ignored.

Fluid-solid coupling effect stress field and displacement field of the excavation surface. The calculate results are shown in Table 2 when the support pressure ratio at 0.785 , from the table, it is known that because of different influence of fluid-solid coupling the changes of displacement and stress are different, but the shape of contour line is regular. The displacement increase greatly, the biggest horizontal displacement increased by $60.57 \%$, the biggest vertical displacement increased by $40.02 \%$. The seepage is harm to the stress distribution of the tunnel unit around the groundwater, the unit compressive stress decreases to $19.86 \%$ while the tensile stress increased to $42.04 \%$. The change of stress is small compared with displacement, but stress of the excavation surface is concentrated and harmful to stress distribution. It is possible to suffer shear failure and become more unstable.

Table 2: The compare the max displacement and stress under seepage and no seepage

\begin{tabular}{ccccccc}
\hline $\begin{array}{c}\text { Groundwate } \\
\mathrm{r}\end{array}$ & $\begin{array}{c}\text { The } \\
\text { maximum } \\
\text { horizontal } \\
\text { displacement } \\
(\mathrm{mm})\end{array}$ & $\begin{array}{c}\text { The } \\
\text { maximum } \\
\text { vertical } \\
\text { displacement } \\
(\mathrm{mm})\end{array}$ & $\begin{array}{c}\text { The first } \\
\text { principal } \\
\text { tensile } \\
\text { stress } \\
(\mathrm{KPa})\end{array}$ & $\begin{array}{c}\text { The first } \\
\text { principal } \\
\text { compressive } \\
\text { stress }(\mathrm{KPa})\end{array}$ & $\begin{array}{c}\text { The third } \\
\text { principal } \\
\text { tensile } \\
\text { stress } \\
(\mathrm{KPa})\end{array}$ & $\begin{array}{c}\text { The third } \\
\text { principal } \\
\text { compressive } \\
\text { stress }(\mathrm{KPa})\end{array}$ \\
\hline Yes & 328.6 & 83.01 & 5.762 & -453.2 & 1.023 & -1218.2 \\
No & 129.54 & 46.467 & 3.3408 & -363.17 & 0.5632 & -1136.8 \\
A little & 199.06 & 36.543 & 2.4212 & -90.03 & 0.4597 & -81.4 \\
More & $60.57 \%$ & $44.02 \%$ & $42.02 \%$ & $19.86 \%$ & $44.9 \%$ & $6.68 \%$ \\
\hline
\end{tabular}

Pore water pressure influence the plastic zone around the excavation face. It can be seen from Figure $6(a, b)$ that plastic region of tunnel excavation face extends to the $20 \mathrm{~m}$ front of the excavation face under seepage when the support pressure ratio is 0.785 . It almost collapse and need immediate support. On the contrary, the tunnel is stable and the plastic region is small.

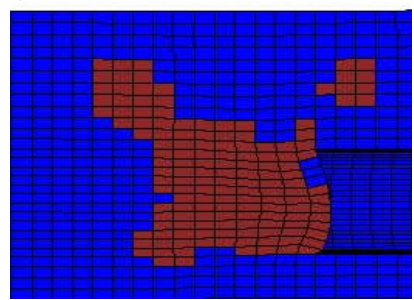

(a) seepage

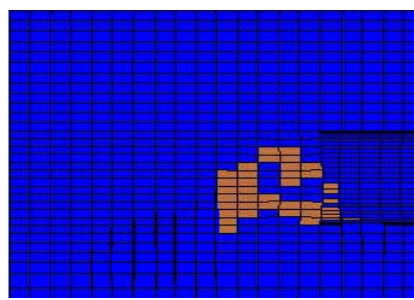

(b) no seepage

Fig. 6 The plastic zone 


\section{Conclusion}

(1) Shanghai Yangtze River Tunnel as the engineering background, based on the fluid solid coupling theory, it is discovered that Seepage have a great influence on the stress field, and the change is regular.

(2) According to the theory of stability, when the horizontal displacement of the point in the center of excavation face increases rapidly and the displacement emerges abrupt change, the support pressure is limit support pressure. This method provides a reference to ensure support pressure of excavation face in engineering. The limit support pressure which can ensure the stability of the tunnel excavation face is equal to the sum of effective support pressure acting on the excavation face and the penetration.

(3) It is discovered from the comparison of plastic state, stress and displacement under seepage, that seepage pressure is the main port of total support pressure. Fluid-solid coupling effect is harmful to the stability of tunnel excavation face.

\section{Acknowledgements}

This work was financially supported by Scientific and Technical Research Foundation for Young Scientist of the Higher Education Institutions of Hebei Province (QN2014119), Hebei province Science \& Technology Pillar Program (12276124).

\section{References}

[1] Ji Xiaoming, Wang Yuhui. Hydromechanical coupling analysis of tunnel excavation process[J].Chinese Journal of Underground Space and Engineering,2005, 1(6):848-852. (in Chinese).

[2] PIERRE CHAMBON, JEAN-FRANCOIS CORTE. Shallow tunnels in cohesionless soil: Stability of tunnel face(J]. ASCE Jounralof G eotechnical Engineering,1994,20(7):1148- 1165.

[3] G.ANAGNOSTOU and K.KOVARI. Face Stability Conditions with Earth Pressure Balanced Shields [J]. Tunnelling and Underground Space Technology, 1996,11(2): 165-173.

[4] IN-MO LEE, JAE-SUNG LEE, SEOK-WOO NAM. Effect of seepage force on tunnel face stability reinforced with multi-step pipe grouting[J]. Tunnelling and Underground Space Technology, 2004(19):551-565.

[5] W.BROERE. Face Stability Calculation for a Slurry Shield inHeterogeneous Soft Soils[J]. Tunnels and Metropolises, 1998: 215-218.

[6] Qin Jian-she. Study on Face Deformation and Collapse of Earth Pressure Shield Tunnel [D]. Hehai University, 2005. ( in Chinese).

[7] M.A. Meguid and R.K. Rowe. Stability of D-shaped tunnels in a Mohr-Coulomb material under anisotropic stress conditions. DCan. Geotech. J. 2006(43): 273-281. 